\title{
Collaborative Governance Dalam Pengelolaan Integrated Community Shelter Pasca Bencana Di Kota Palu
}

\author{
Daswati Daswati ${ }^{1)}$, Muhammad Ahsan Samad ${ }^{1}$, Ismail Suardi Wekke ${ }^{2)}$ \\ ${ }^{1}$ Universitas Tadulako, Palu \\ ${ }^{2)}$ Sekolah Tinggi Agama Islam Negeri (STAIN) Sorong, Papua Barat \\ Email: ahsansamad@untad.ac.id \\ Disajikan dalam \\ International Symposium on Indonesian Politics 2019 \\ Politics and Citizenship: Challenges on Democracy Consolidation in Digital Era \\ Semarang, Indonesia; 25-26 Juni, 2019
}

\begin{abstract}
ABSTRAK
Artikel ini menceritakan keterlibatan lembaga kemanusiaan dalam proses rekonstruksi pasca bencana di Kota Palu, Sigi dan Donggala. Kehadiran lembaga kemanusiaan ini sangat diperlukan untuk membantu proses percepatan rekonstruksi. Dalam menjalankan misi kemanusiaan itu, lembaga ini diharapkan agar terkoordinasi dengan baik oleh otoritas pemerintah/negara. Pengelolaan Integrated Community Celter yang diharapkan mampu membantu proses rekontruksi pasca bencana ternyata juga masih terkendala dalam pola koordinasi. Pola koordinasi yang terjadi cenderung kurang terbuka dalam memberikan dan menyalurkan bantuan kepada para korban. Melaui tulisan ini ditemukan adanya kelemahan dari regulasi negara dalam mengontrol dan mewadahi keterlibatan lembaga kemanusiaan dalam proses rekontsruksi. Pendekatan collaborative governance dalam pengelolaan Integrated Community Celter muncul sebagai alternatif solusi dalam menjawab problematika tersebut.
\end{abstract}

Kata Kunci : Collaborative Governance, Integrated community Shelte, Koordinasi 


\title{
Collaborative Governance in the management of Integrated Community Shelters post disaster (ICS) in the City of Palu
}

\author{
Daswati Daswati ${ }^{1)}$, Muhammad Ahsan Samad ${ }^{1)}$, Ismail Suardi Wekke ${ }^{2)}$ \\ ${ }^{1}$ Universitas Tadulako, Palu \\ ${ }^{2}$ Sekolah Tinggi Agama Islam Negeri Sorong, Sorong \\ Email: ahsansamad@untad.ac.id
}

\begin{abstract}
Abstrac
This article tells the involvement of humanitarian organizations in the post-war reconstruction process of disaster in The city Of Palu Palu, Sigi and Donggala Regencies. The presence of humanitarian organizations is urgently needed to help the process of acceleration of reconstruction. In carrying out its humanitarian mission, it is expected that these institutions are coordinated by the authority of the Government/state. Management of Integrated Community Celter expected able to help the process of reconstruction post disaster apparently also still constrained in the pattern of coordination. Coordination pattern which is less likely to occur in delivering open and funneling aid to victims. this paper found that the existence of the weakness of the State in controlling and embody the humanitarian agency's involvement in the process of reconstructions. Collaborative approach to governance in the management of Integrated Community Celter appears as an alternative solution in the answer to these problems.
\end{abstract}

Key Words : Collaborative Governance, Integrated community Shelter, Coordination 


\section{PENDAHULUAN}

Sepekan sejak bencana melanda kota Palu, Sigi dan Donggala (28/09/2019), masih menyisakan duka mendalam bagi para masyarakat, sebagian besar warga selamat masih memilih untuk tinggal di tenda pengungsian karena masih trauma dan gempa kecilpun masih sering terjadi. Selain itu, masyarakat kota juga menderita trauma parah, karena memang begitu terkena gempa susulan tanpa henti diintensifkan dengan menderu suara dari bawah tanah bumi yang banyak ditakuti bahwa kota Palu akan runtuh ke dasar laut (Wekke, Rajindra, et al.) Saat fase darurat telah mulai berangsur-angsur pulih, pemulihan pasca bencanapun segera dilakukan. Lembaga kemanusiaan baik dalam dan luar negeri silih berganti membantu proses pemulihan pasca bencana di kota Palu.

Pemerintah dalam merespon upaya bantuan bencana, memerlukan dukungan dari organisasi organisasi pemberi bantuan, seperti yang dikemukakan oleh Helsloot dan Ruitenberg (2004), bahwa pemerintah di mana bencana terjadi tidak mungkin mampu untuk merespon segala aspek dalam upaya respon dan pemulihan bencana secara sendirian. Upaya respon dan pemulihan bencana tidak hanya dilakukan oleh pemerintah, namun juga direspon oleh Non Govermental Organizations atau Lembaga Swadaya Masyarakat (LSM), perusahaan perusahaan, lembaga dan institusi swasta, militer, organisasi kemasyarakatan, dan masyarakat dari daerah lain.(Olimpiade \& Tulis, 2009). Sebuah konferensi dunia tentang Reduksi Bencana Alam dilaksanakan di Yokohama, Jepang. Konferensi ini menekankan bahwa setiap negara memiliki kedaulatan dan tanggungjawab utama untuk melindungi warganya, infrastruktur dan kepentingan nasional, aset sosial atau ekonomi dari dampak bencana alam. Konferensi Yokohama kemudian merumuskan strategi dan rencana aksi bagi dunia yang lebih aman. Basis dari strateginya adalah kesadaran dan pengakuan bahwa bencana alam terus menimpa dan meningkat dalam magnitude, kompleksitas, frekuensi dan dampak ekonomi.(Permana, n.d.)

Berbagai kerja sama antar pemangku kepentingan dalam penyelenggaraan pemerintahan juga dilakukan sebagai suatu usaha dan respon pemerintah dalam kegiatan penanganan masalah publik. Kebutuhan akan partner dan asistensi ini menunjukkan adanya urgensi akan tata kelola yang baik yang terpadu dengan pendekatan collaborative governance.
Collaborative governance menekankan pada kerjasama antar aktor terkait yang titik tekannya ada pada dialog serta sustainabilitas koordinasi dan kooperasi. (Novita, Brawijaya, \& Timur, 2018). Istilah kerja sama antar pemangku kepentingan yang melibatkan pemerintah, swasta, dan masyarakat dapat diartikan sebagai collaborative governance. Collaborative governance juga diperlukan adanya reformasi dengan mensinergikan berbagai perspektif pemangku kepentingan, lebih dekat dengan masyarakat, dan memperluas kerjasama dengan pihak lain untuk memenuhi kebutuhan sumber daya, dan perekrutan SDM. (Irawan, 2016).

Undang-Undang No. 24 Tahun 2007, tentang Penanggulangan Bencana mengamanatkan pemerintah sebagai penyelenggara utama yang bertanggungjawab terhadap pelaksanaan kegiatan rekonstruksi pasca bencana termasuk sektor perumahan. Akan tetapi, dengan keterbatasan yang dimiliki, perlu didorong peran serta dari berbagai pihak, seperti lembaga swadaya masyarakat, pihak swasta, badan bantuan luar negeri dan donor, sehingga bantuan pemulihan dapat dilaksanakan dengan efektif. Di sisi lain, masyarakat yang terkena bencana, memiliki keterbatasan untuk memulihkan kembali kondisinya karena memiliki keterbatasan sumber daya.(Sagala, Situngkir, \& Wimbarda, 2019).

Adanya keterlibatan lembaga kemanusiaan dalam penanganan pasca bencana di Kota Palu tentunya sangat membantu pemerintah dalam proses rekonstruksi. Beberapa lembaga kemanusiaan silih berganti berdatangan ke Kota Palu, Kabupaten Sigi dan Kabupaten Donggala, baik itu lembaga kemanusiaan skala nasional sampai kepada lembaga kemanusiaan bertaraf internasional.

Integrated Community Shelter (ICS) atau kawasan pemulihan terpadu, adalah sebuah program dari salah satu lembaga kemanusiaan berskala Nasional, Organisasi kemanusiaan Aksi Cepat Tanggap (ACT). Dalam misi kemanusiannya ACT kemudian membangun kawasan pemulihan terpadu di Sulawesi Tengah. Shelter saat ini sudah dibangun di sektiar 5 lokasi yang tersebar di Kota Palu, Kabupaten Donggala dan Kabupaten Sigi.

Salah satu shelter yang berada di kota Palu, terletak di sebuah lapangan dan terdiri dari 96 unit bangunan. Namun dalam proses pelaksanaannya masih ditemukan beberapa kendala, utamanya pada pola Collaboration, baik itu Collaboration antara fihak ACT dan 
Pemerintah setempat, atau Collaboration antara fihak ACT dan sesama Lembaga kemanusiaan lainnya.

Collaborative Governance dapat diartikan sebagai sebuah pengaturan yang mengatur satu atau lebih lembaga publik secara langsung terlibat dengan pemangku kepentingan non publik dalam proses pengambilan keputusan kolektif bersifat formal, berorientasi konsensus, dan musyawarah yang bertujuan untuk membuat atau mengimplementasikan kebijakan publik atau mengelola program atau aset publik.(Febrian, 2016). Landasan untuk teori Collaborative Governance bersifat integratif dalam beberapa cara. Definisi untuk Collaborative Governance lebih luas daripada apa yang biasa dilihat dalam literatur, dengan memanfaatkan dan menerapkan pengetahuan dan konsep dari berbagai bidang seperti administrasi publik, resolusi konflik, dan manajemen lingkungan, antara lain.(Emerson, Nabatchi, \& Balogh, 2011)

Tulisan ini mencoba menganalisis Collaborative Governance dalam pengelolaan Integrated Community Shelter (ICS) pasca bencana di kota Palu

\section{METODE PENELITIAN}

Studi dilakukan di salah satu lokasi Integrated Community Shelter (ICS) yaitu di desa Lolu Kecamatan Sigi Biromaru Kabupaten Sigi. Metode yang digunakan adalah pendekatan deskriptif kualitatif yang menggambarkan isuisu prioritas dan strategis Collaborative Governance dalam hal pengelolaan ICS, sedangkan teknik pengumpulan data dilakukan inventarisasi data primer dan sekunder. Untuk data primer diperoleh berdasarkan data empiris lapangan melalui tehnik Wawancara mendalam (depth interview) dan Observasi non Partisipan dan Diskusi kelompok terarah (Focus Group Discussion).

Sedangkan data sekunder meliputi penelusuran berbagai sumber dan literatur baik dari dokumen pemerintah maupun pemberitaan media massa cetak dan elektronik, jurnal dan buku-buku yang terkait dengan collaborative governance dan inovasi kebijakan Selanjutnya data yang terkumpul, dianalisis dengan analisis kualitatif, dengan model interaktif Miles dan Huberman(Sururi, Ilmu, \& Raya, 2018).

\section{HASIL PENELITIAN DAN DISKUSI}

\section{Kerja Sama Lembaga Kemanusiaan dan Masyarakat Lolu}

Gempa, Tsunami dan Likuifaksi yang melanda Kota Palu, Kabupaten Donggala dan Kabupaten Sigi pada tanggal 28 September 2018 menyisakan duka yang mendalam bagi para korban. Salah satu desa yang terdampak bencana adalah Desa Lolu yang berada di Kabupaten Sigi. Gempa dengan berkekuatan 7,4 S.R berhasil memporak porandakan pemukiman warga. Korban jiwa berjatuhan dan kerugian material tidak dapat terhindarkan. enanganan darurat dampak gempa bumi dan tsunami di Sulawesi Tengah melanjutkan. Percepatan pemulihan bencana terus diintensifkan, khususnya dalam memenuhi kebutuhan dasar para pengungsi, layanan medis, peningkatan infrastruktur dasar, dan normalisasi kehidupan masyarakat.(Wekke, Sabara, et al., n.d.)

Enam bulan waktu berjalan, trauma yang dirasakan warga masih sangat terasa di Desa tersebut. Menurut hasil pengamatan lapangan, Desa Lolu mendapatkan bantuan dari beberapa pihak lembaga kemanusiaan seperti ACT, BUMN, Kompas, NU Peduli, Rotasi, Islamic Relief, dan Dompet Dhuafa. Dan pihak yang bekerja sama penuh dengan masyarakat Desa Lolu adalah Lembaga Kemanusiaan ACT. Pihak ACT mendirikan huntara yang memiliki kontrak selama tiga tahun dan juga paket sembako kepada warga selama 3 bulan. Di Desa Lolu terdapat 5 dusun dimana letak huntara yang dibangun ACT berada di dusun 2 . Huntara tersebut dibangun 2 bulan setelah bencana melanda Pasigala.

Proses masuknya lembaga kemanusiaan ke Desa Lolu tidak terlepas dari pengawasan pemerintahan desa. Setiap lembaga kemanusiaan yang akan memasuki Desa Lolu wajib untuk meminta izin kepada pihak desa. Walaupun ada beberapa pihak yang tidak melakukan perizinan, hasil akhirnya akan tetap kembali kepada pemerintahan desa. Karena pada akhirnya terkait bantuan yang masuk akan di data oleh pihak desa sendiri.

Lembaga kemanusiaan ACT yang bertanggung jawab penuh terhadap huntara yang didirikan di desa Lolu pun tidak terlepas 
dari kerja sama yang dilakukan bersama aparat desa. Mulai dari perizinan untuk mendirikan huntara, sampai pada pendataan siapa saja yang berhak untuk menempati huntara tersebut. Ada lima spesifikasi warga yang berhak menerima huntara. Yaitu, memiliki anak kecil, kerusakan rumah yang cukup parah, kerusakan rumah ringan,orang hamil, orang tua dan orang yang lanjut usia . Tujuan didirikannya huntara selain untuk memberikan bantuan material kepada warga, juga bertujuan untuk membangkitkan dan memberdayakan perekonomian warga di desa Lolu.

\section{Lembaga Kemanusiaan Aksi Cepat Tanggap}

Salah satu lembaga kemanusiaan yang memiliki peran besar dalam membantu masyarakat di Kota Palu, Donggala dan Sigi adalah lembaga kemanusiaan Aksi Cepat Tanggap (ACT). ACT mulai masuk ke Kota Palu pada tanggal 29-30 September 2018 bersama dengan personil relawan dari Makassar,Gorontalo dan Sulawesi Barat. Ada beberapa program yang dilakukan lembaga kemanusiaan tersebut. Salah satunya adalah pembangunan huntara. Setidaknya ada 10 titik huntara yang telah di bangung oleh pihak ACT selama menjadi relawan Pasigala. Titik huntara tersebut yaitu Kota Palu, Desa Lolu, Desa Wani, Desa Sumari, Desa Buluri Ulu Jadi, Desa Sidera, Desa Lagaleso, Desa Sibalaya, Desa Lolove dan Desa Fabilester.

Pada awalnya untuk membangun sebuah huntara pihak ACT hanya bekerja sama dengan pemerintahan desa setempat. Namun sekarang, untuk membangun huntara ACT harus mendapatkan SK dari Walikota dan Bupati yang bersangkutan. Dalam pemberian logistik, ACT bekerja sama dengan lembaga kemanusiaan lainnya seperti sublapster dari lokal sampai luar negeri, dan BWJ dari Jepang yang bekerja sama dengan BKPU.

\section{Pendekatan collaborative governance dalam pengelolaan Integrated Community Celter;}

\section{Commitment to a common purpose (komitmen terhadap tujuan)}

Kolaborasi yang terjalin berdasarkan pada tujuan, visi dan misi yang sama, terkait dengan komitmen dari masing-masing stakeholders. Dalam penerapannya dilapangan, lembaga kemanusiaan yang berasal dari luar negeri seakan hanya memberikan bantuan tanpa adanya riset dan koordinasi yang baik kepada pemangku kepentingan dalam hal ini otoritas pemerintah setempat. Sehingga terlihat beberapa shelter yang didirikan oleh lembaga kemanusiaan lainnya cenderung terbengkalai dan tidak dimanfaatkan oleh masyarakat korban bencana. Dikarenakan salah salah satu diantaranya adalah letak huntara yang jauh dari pusat aktifitas masyarakat.

\section{Trust among the participants}

(kepercayaan di antara para partisipan)

Terkait dengan kepercayaan atas informasi-informasi atau data dari setiap stakeholders dalam kolaborasi pengelolaan Integrated Community Celter. Pemerintah setempat berdasarkan hasil penelitian belum memberikan informasi yang valid terkait jumlah korban pasca bencana, pada akhirnya penyaluran logistik dan bantuan dari lembaga kemanusiaan belum tersebar secara merata, bahkan ada kasus Desa Wani, warga penduduk asli desa tersebut tidak terdata oleh otoritas pemerintah setempat sebagai salah satu korban bencana, dan pada akhirnya keluarga tersebut tidak mendapatkan hak untuk menempati salah satu hunian sementara yang dibangun oleh lembaga kemanusiaan di desa tersebut.

\section{Clarity in Governance}

\section{(kejelasan dalam tata kelola)}

Dalam hal kejelasan tata kelola ICT terlihat bahwa antara stakeholder dan lembaga kemanusiaan telah memiliki aturan yang jelas, seperti halnya kesepakatan/kontrak kerjasama yang jelas tentang jangka waktu penggunaan lahan ICT, hal ini dapat dilihat dari pengakuan pengelola ICT bahwa antara mereka dan otoritas pemerintah setempat sampai hari ini masih dapat berkoordinasi dengan baik perihal perizinan penggunaan lahan. Self determination atau kebebasan untuk menentukan bagaimana kolaborasi akan dijalankan dan siapa yang diijinkan terlihat sudah terlaksana, ini dibuktikan dengan bebasnya lembaga kemanusiaan baik dalam/luar negeri untuk mengadakan kerjasama dengan pemangku kebijakan setempat. Network management atau dukungn semua anggota tanpa konflik dan pertentangan dalam pencapaian tujuan belum 
terlihat maksimal, terbukti dari beberapa penduduk asli yang lokasinya terdampak bencana, belum mendapatkan perhatian berupa pendirian huntara sehingga kadang menimbulkan konflik internal antar warga sehingga kolaborasi yang terjadi belum memenuhi aspek kejelasan governancenya.

\section{Access to authority \\ (akses terhadap otoritas)}

Akses terhadap otoritas yakni tersedianya ukuran-ukuran ketentuan prosedur yang jelas yang diterima secara luas. Pemerintah dan Lembaga Kemanusiaan telah memiliki standart tertentu terkait dengan penanganan korban bencana sesuai dengan tugas dan fungsi yang telah diatur dalam undang-undang nomor 24 tahun 2007 tentang penanggulangan bencana. Pada pasal 1 ayat 12 disebutkan bahwa Rekonstruksi adalah pembangunan kembali semua prasarana dan sarana, kelembagaan pada wilayah pascabencana, baik pada tingkat pemerintahan maupun masyarakat dengan sasaran utama tumbuh dan berkembangnya kegiatan perekonomian, sosial dan budaya, tegaknya hukum dan ketertiban, dan bangkitnya peran serta masyarakat dalam segala aspek kehidupan bermasyarakat pada wilayah pascabencana. Sehingga akses terhadap otoritas telah dilaksanakan sepenuhnya oleh kedua fihak.

\section{KESIMPULAN}

Berdasarkan analisis yang dilakukan pada bagian sebelumnya, penelitian ini memberikan empat kesimpulan yang dapat diberikan terkait dengan Collaborative Governance dalam pengelolaan Integrated Community Shelter (ICS) pasca bencana di kota Palu.

Pertama komitmen terhadap tujuan, dalam melaksanakan komitmennya beberapa lembaga kemanusiaan masih kurang berkoordinasi dengan pemangku pemerintahan setempat utamanya lembaga kemanusiaan yang berasal dari luar negeri, berdasarkan hasil analisis peneliti, kejadian ini akibat dari kurang sigapnya pemerintah kota setempat dalam menghadapi bencana.

Kedua kepercayaan di antara para partisipan, informasi dari beberapa warga korban bencana menginformasikan bahwa mereka sama sekali belum tersentuh bantuan sampai sepekan setelah bencana, hal ini dapat peneliti simpulkan bahwa pemerintah juga tidak sigap dalam hal memberikan data yang akurat tentang korban serta lokasi pengungsian masing-masing warga terdampak, sehingga pengalokasian logistik terkesan tidak merata.

Ketiga kejelasan dalam tata kelola, dalam pengeloaan ICT terlihat bahwa salah satu lembaga kemanusiaan Nasional dalam hal ini ACT telah memperlihatkan aturan dan koordinasi yang jelas dengan aparat pemerintah dimana lokasi ICT tersebut didirikan, namun dalam hal kerjasama antar sesama lembaga kemanusiaan masih terlihat adanya miss koordinasi, ini dibuktikan dengan pengamatan dilapangan, bahwa lembaga kemanusiaan lain tidak dapat menyalurkan bantuan kepada masyarakat penghuni ICT yang didirikan oleh lembaga kemnusiaan ACT.

Keempat akses terhadap otoritas, pemerintah dan lembaga kemanusiaan nasional, dalam hal ini ACT terlihat sudah saling memahami alur serta prosedural dengan jelas, terlihat bahwa antara pemerintah desa dimana lokasi ICT berdiri, sampai hari ini belum terlihat adanya kelemahan/ masalah dari sisi hukum serta aturan positif lainnya.

\section{REFERENSI}

Emerson, K., Nabatchi, T., \& Balogh, S. (2011). An Integrative Framework for Collaborative Governance, (June 2009), 1-29. https://doi.org/10.1093/jopart/mur011.

Febrian, R. A. (2016). Collaborative Governance Dalam Pembangunan Kawasan Perdesaan (Tinjauan Konsep dan Regulasi ), II, 200 208.

Irawan, D. (2016). ( Studi Deskriptif Proses Pemerintahan Kolaboratif Dalam Pengendalian Pencemaran Udara di Kota Surabaya ), 1-11.

Novita, A. A., Brawijaya, U., \& Timur, J. (2018). Jurnal Ilmiah Administrasi Publik ( JIAP ) Collaborative Governance dan Pengelolaan Lingkungan Hidup di Kawasan, 4(1), 27-35.

Olimpiade, P., \& Tulis, K. (2009). Proceeding Olimpiade Karya Tulis Inovatif (OKTI) 2009, 1-14.

Permana, O. R. (n.d.). Mengubah paradigma penanganan bencana di indonesia.

Sagala, S., Situngkir, F., \& Wimbarda, R. (2019). Interaksi Aktor dalam Rekonstruksi Rumah Pascabencana Gempa Bumi, 29(2), 217-226.

Sururi, A., Ilmu, F., \& Raya, U. S. (2018). Collaborative Governance Sebagai Inovasi 
Kebijakan Strategis (Studi Revitalisasi Kawasan Wisata Cagar Budaya Banten Lama), 25(1).

Wekke, I. S., Rajindra, R., Pushpalal, D., Samad, M. A., Yani, A., \& Umam, R. (2019, March 19). Educational Institution on Responding Disasters in Palu of Indonesia. https://doi.org/10.31227/osf.io/drc8q.

Wekke, I. S., Sabara, Z., Samad, M. A., Yani, A., Abbas, T., \& Umam, R. (2019). Earthquake, Tsunami, And Society Cooperation: Early Findings In Palu Of Indonesia Post Disaster. https://doi.org/10.31227/osf.io/xmcyn. 